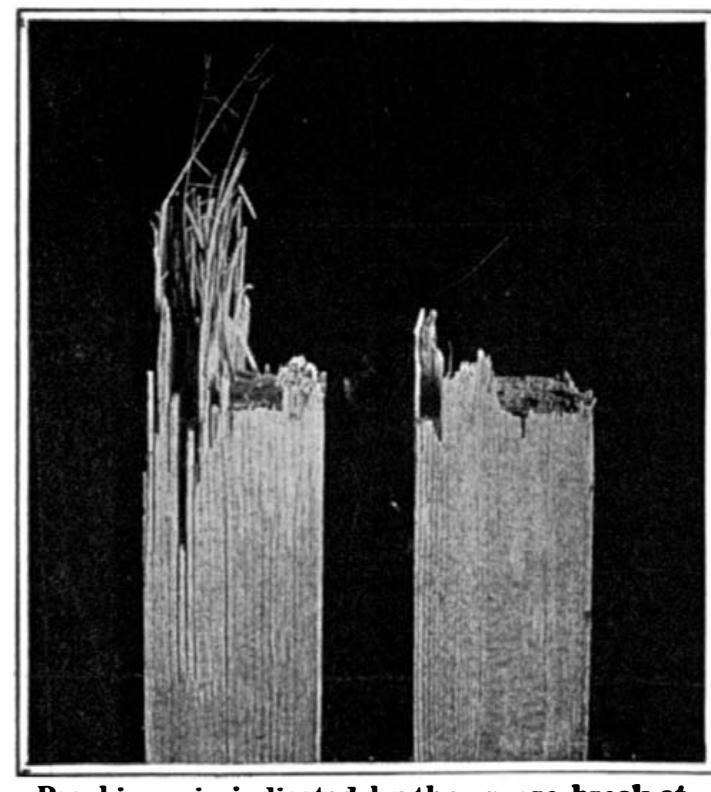

Brashiness is indicated by the square break at (Both specimens Sitka spruce)
(night, toughness by the splintered

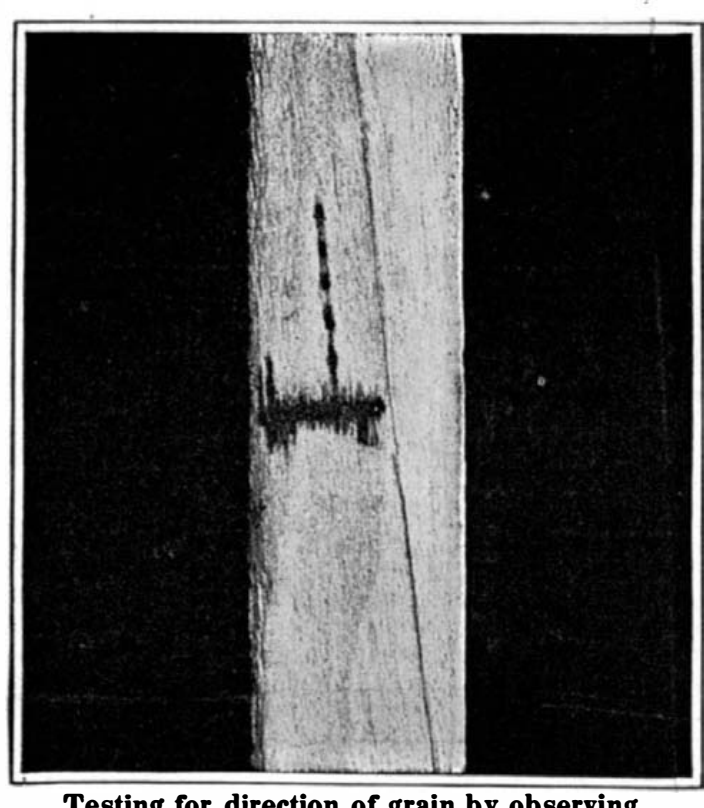

Testing for direction of grain by observing the pores of the wood

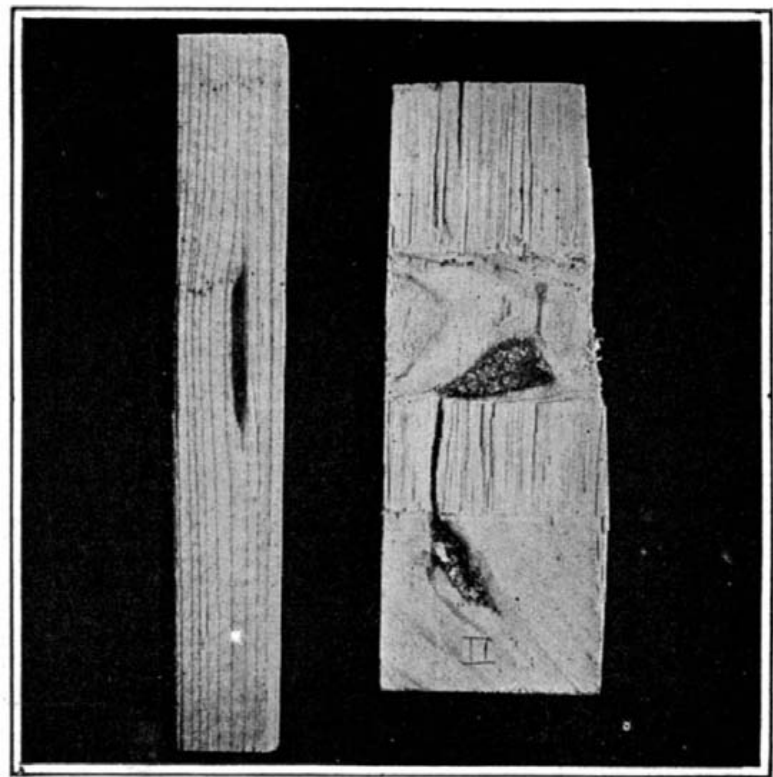

Pitch pockets, a very common defect in spruce, or located near the surface

\title{
Defects in Airplane Woods
}

\section{Judging the Quality of the Timber That Goes into Our Fleet of Fliers}

\section{By Samuel J. Record}

ThE "wooden components of an airplane represent nation begins with the species and follows through all the various stages of manufacture and assembly. One kind of wood may be rejected because it has a bad reputation while another is passed by because its proper-
ties are unknown. Thanks to the long series of laboratory tests made by the United States Forest Service, this war did not find us unprepared so far as a workin nately this cannot be said for the products of the vast forest regions beyond our southern boundary. Merely to enumerate the species used is to tell only
a part of the story of wood selection. While every species tends to preserve certain racial characteristics, and to produce woods of a certain sameness, yet each tree within that species possesses a distinct individuality. Wood is a natural product, a structure designed to meet in detail, is as infinitely variable as the conditions which A to produce it. standardization. In this it differs from many other structural materials such as metals and concrete. There are, to be sure, tables giving unit strength values for woods; but these are merely averages of many tests and are not directly applicable to any given piece of material. They serve many useful purposes, however, not the

In selecting wood for a particular purpose one of the fundamentals is to be able to correlate strength values with features which are readily discernible; to know the signs of strength and the signs of weakness. The best criterion of strength is the weight of the cry wo $11 / 2$ times as much as water and is practically uniform for all species. The more wood substance per unit of volume or the greater the dens

harder and stronger it will be. construction it might be assumed that the less w.jight a given specimen of wood has the better. There is, however, for every wood a certain minimum limit beyond which reduction in weight is attended by brashiness and brittleness. The wood produced late in the life of an old tree is almost invariably light and brash, with little reserve strength beyond the limit of elasticity. roneously called the heart, is invariably weaker than roneously called the heart, is invariably weaker than our strongest and toughest woods, is so punky and brash as to be absolutely useless for any purpose requiring strength. Kiln drywill induce permanent brittleness in wood. There are various methods for detecting brash or brittle material. is an almost certain inis an almost certain inthe fracture when a specimen is broken in bending is another. A tough wood will give way gradually, with a fibrous or splintery fracture, while a brittle
one will snap off short one will snap off short same effect can be approximated by goueing the surface of the wood with the point of a knife and noting "picks out" punky. Wood is at its best for most purposes when the grain is straight, that is,
when the fibers lie parallel to the long dimensions of a stick. In such material

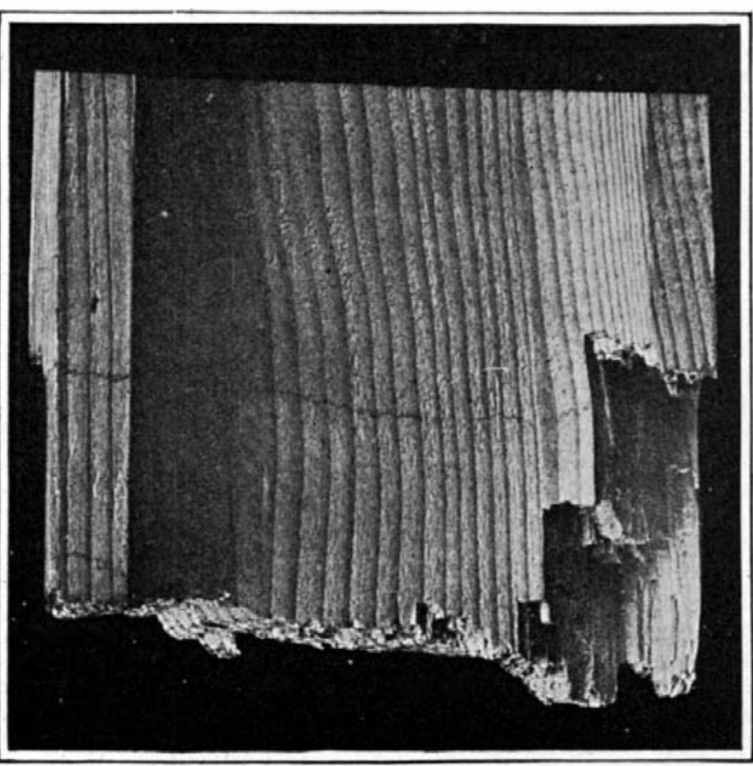

Section of spruce wing beam cut from wood winich was broken in the tree, probably orm throughout and the tendency to warp out of shape at a minimum. Whenever a wooden part is deformed by an external force, as in bending, a portion of th material is stretched, and the resistance offered when this tensile stress is along the fiber may be more than rain. This contin the lateral easoning and other causes.

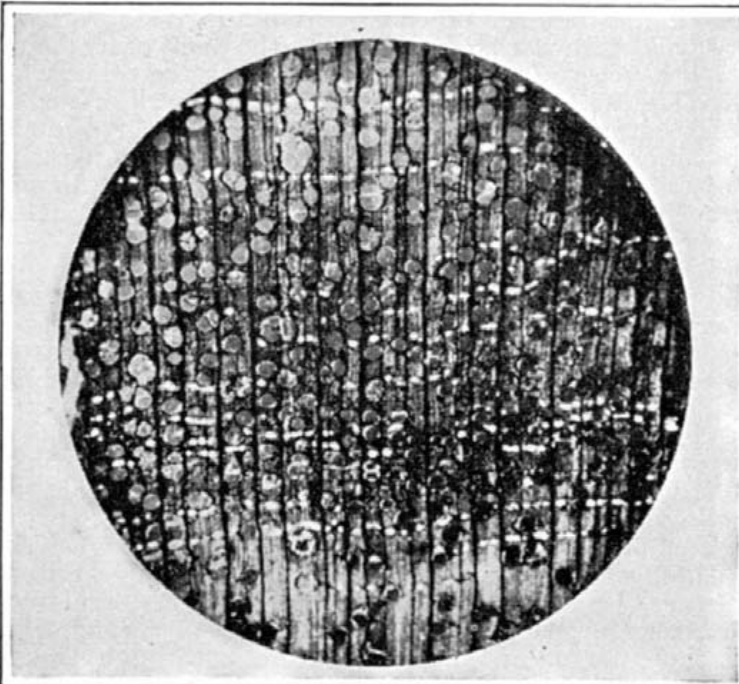

Smooth end of Philippine mahogany, under the glass, shows characteristic rows of white dots which

There are many factors which interfere with straightness of grain. Some trees have their fibers arranged in "torse" wood. Spiral grain is the source of much of this spiral are subject to change, sometimes at such regular intervals that a so-called "ribbon "or "feather prima produced. This is very common in mahogany, prima vera, and tangujle, but owing to the fact that effect of the irregular grain is largely overcome.

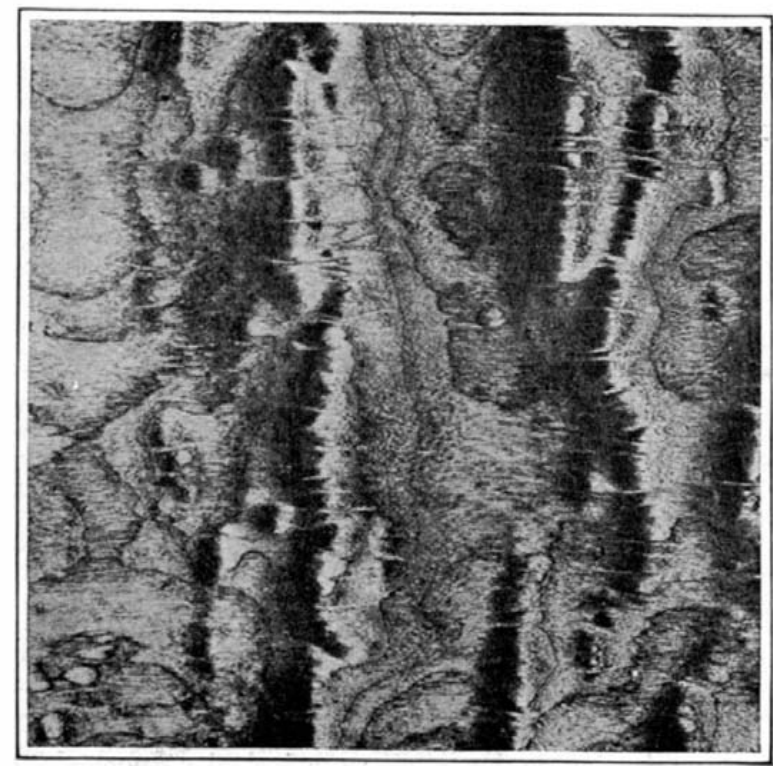

Blister mottle in yellow poplar, believed to be due to the pecking of holes in the live tree
Another form of cross-grain is produced in lumber by the method of sawing and has no reference to the natura mately the same diameter at each end the plane of the saw must be parallel to the axis of growth, while in logs with decided taper, the plane of the saw, for the not the middle of the log. Otherwise the growth ring will be cut across diagonally and the timber weakened accordingly.

Another source of local cross-grain is knots. The bigger the knot the greater the range of the oisturbance. It is largely on this account that knots are such serious qualities and are always disturbing factors. There are also various local irregularities which cannot readily ness in the surface of the tree and to injuries. "blister mottle" which occurs in yellow poplar is believed to be due to injuries caused by sapsucking birds. These also produce "bird-peck" and "rust streaks" in hickory. Some spruce logs show on the outside beneath the times called "bear-scratches." unknown oricin, somedulations in the growth rings on the ends and peculiar minim markings on the surface. They have been The surest way to detect any kind of cross-grain is It must bece the cleft runs. are two planes of cleavage in wood, one following the rays, the other following the growth rings. A stick may be straight-grained so far as one plane of cleavage When the rays and onal with respect to the other. prominently, as in oak, the direction of the grain is of the fibers under the planer, and by the way in which the light is reflected, an effect very noticeable in ma-

hogany. hardwoods, like yellow poplar, the rays and wood fibers are so small that it is often difficult to determine their direction, even with a hand magnifier. This is particularly the case when the specimen is cut quarteracross the ends. Splitting of course, would spoil the crocimen. In such cases, the ink test is fairly satisfactory. A pen is drawn across the wood and the ink spreads along the fibers. The pen is then touched to

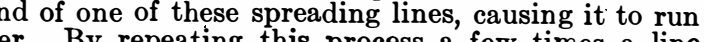
process a few times a line the grain makes with the axis of the piece. If this
line deviates more than 1 line deviates more than inch in 15,20 , or 30 inches,
depending on the class of material inspected, the specimen is not acceptable. In a wood with resin ducts, as in spruce, pine and course of the ducts on the tangential surface is usually distinct enough to show the direction of the grain. It is not generally known that wood is of ten broken outward indication of any fact. Areas of compression failures result, usually in place such as a knot or other defect. Just what causes these compression failures, sometimes designot definitely known, but not definitely known, but 


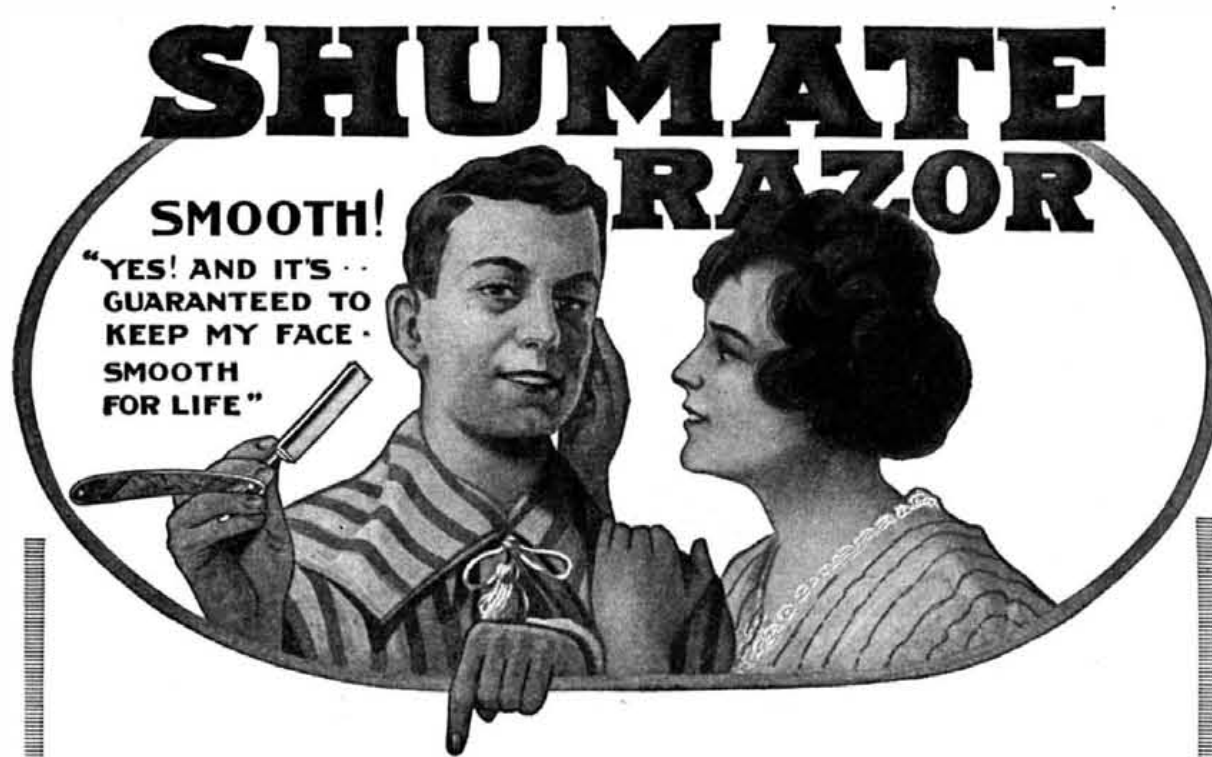

Written Guarantee With Each Razor

This SHUMATE "Barber" razor is so good that we guarantee it to you for life. Here's the reason: The blade is made from tungsten alloy steel, which takes a keener edge than any other steel can-and holds it. You can use it for years without honing. The secret of this wonderful steel is ours alone, and

\section{The Shumate Guarantee}

Buy a SHUMATE "Barber" Razor and use it-not once, but as long as you like. If you say, after an ex

SHUMATE Razors are made by the master cutlers of the world, and for more than 33 years have demonstrated their superior worth to men who appreciato really good razors. United States sailors and soldiers, and more than four
million civilians are using SHUMATES every day. Send for yours today.

$\$ 2 \begin{aligned} & \text { If you want to settle the razor question for life, send us } \$ 2.00 \text { and } \\ & \text { the razor will be forwarded postpaid For those with very otrong, wiry } \\ & \text { beards we recommend our } \$ 3.00 \text { Shumate Razor, epecially ground }\end{aligned}$

NOTE: In remitting, give as your dealer's name, and a chamois-lined, ruse-

Shumate Razor Company, 767 Chestnut St., St. Louis, Mo. Established 1884 Capacity 6,000 Razors Daily
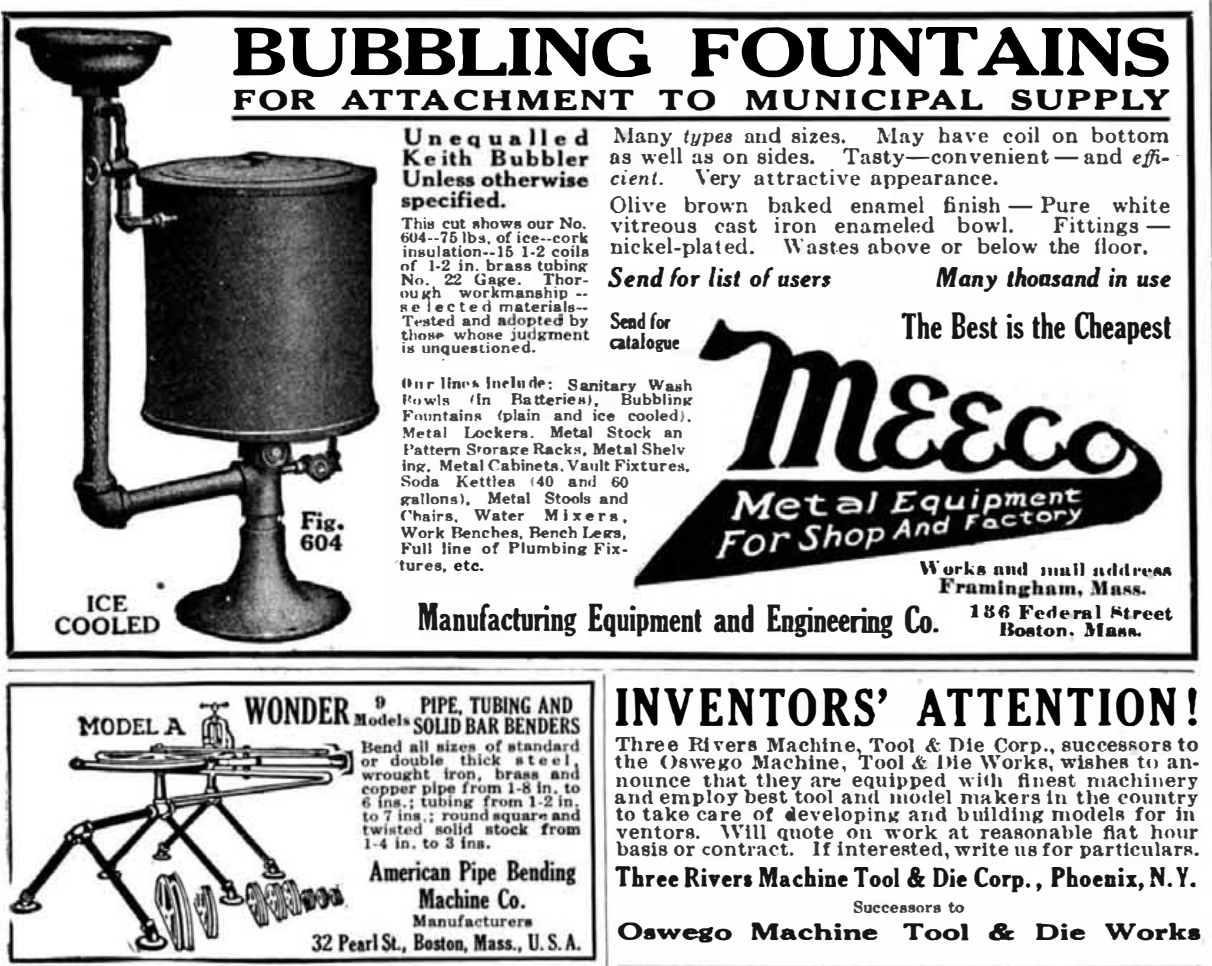

\section{Boaknoed ifiction.- rancinicion}
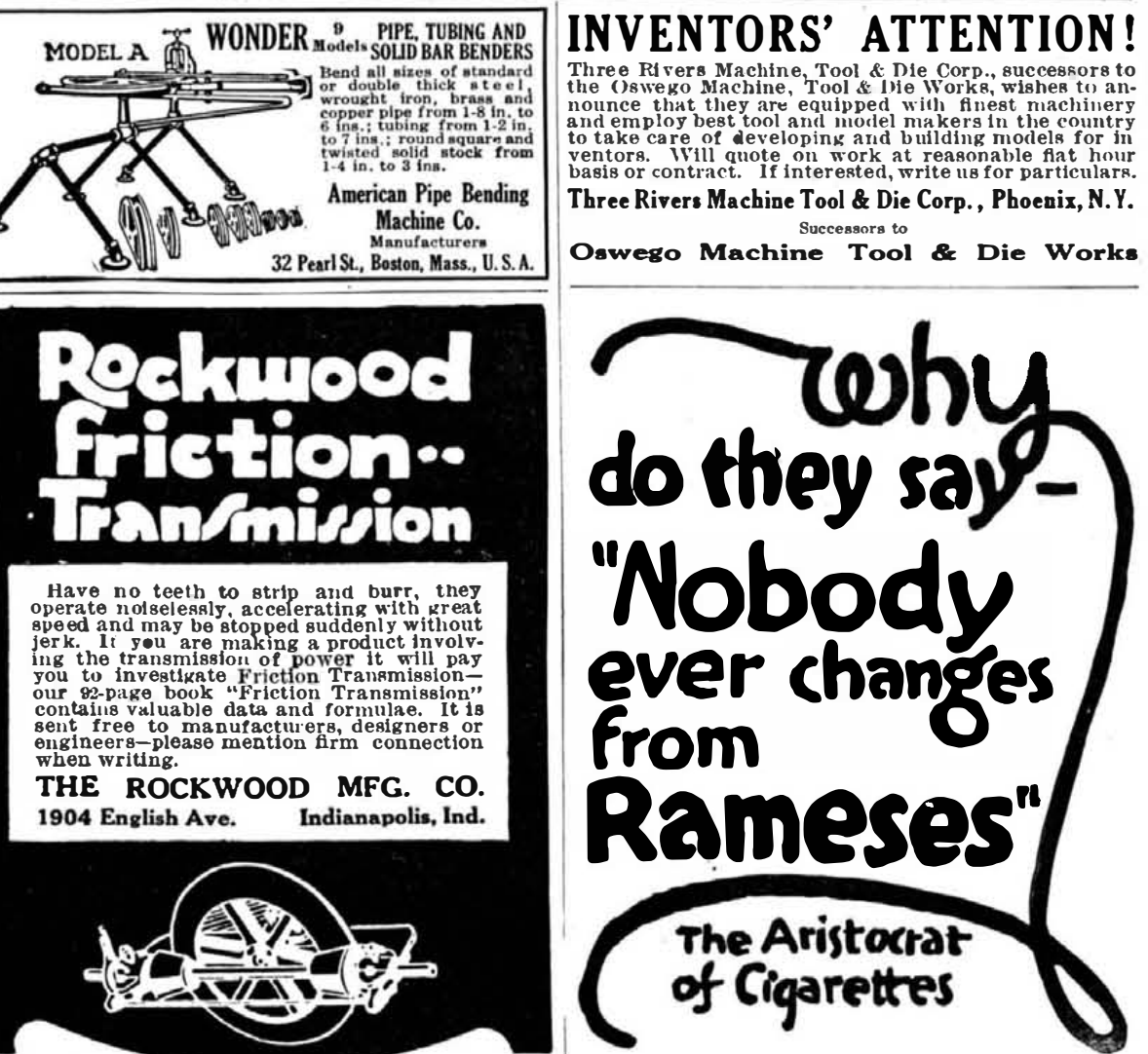

The Current Supplement

from the severe shock when the tre cut down. They constitute a very serious defect and are fairly common in spruce
and mahogany and may appear in any
wood that is somewhat brittle. In ma hogany there is usually enough discolora-
tion to make the break conspicuous, but matter is sometimes complicated by superficial fiber breaks made by the plane
knives, but these can usually be recognized$$
\begin{aligned}
& \text { by } \\
& \text { are } \\
& \text { occ } \\
& \text { que } \\
& \text { dry } \\
& \text { on } \\
& \text { con } \\
& \text { cor } \\
& \text { apa } \\
& \text { the } \\
& \text { nu } \\
& \text { dry } \\
& \text { ch } \\
& \text { but } \\
& \text { fib } \\
& \text { red } \\
& \text { red }
\end{aligned}
$$

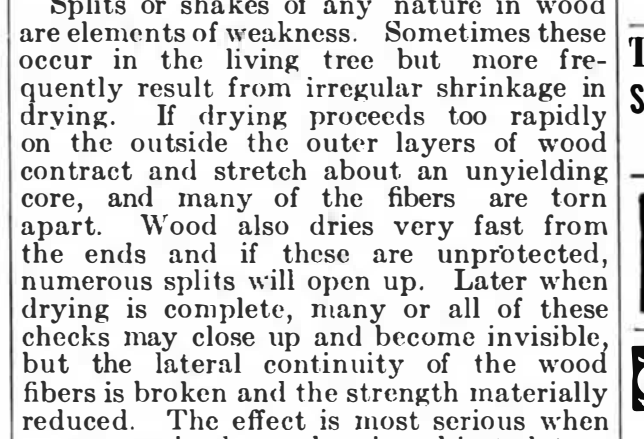

\section{che
the
to
me
with
me
bes.}

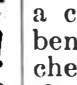
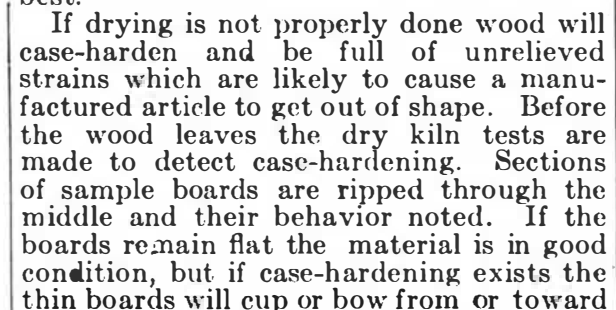

\section{Advertising Classified}

LATHES AND SMALL TOOLS

For Gunsmiths, Tool Makers, Experimental \& Repair Work, etc.
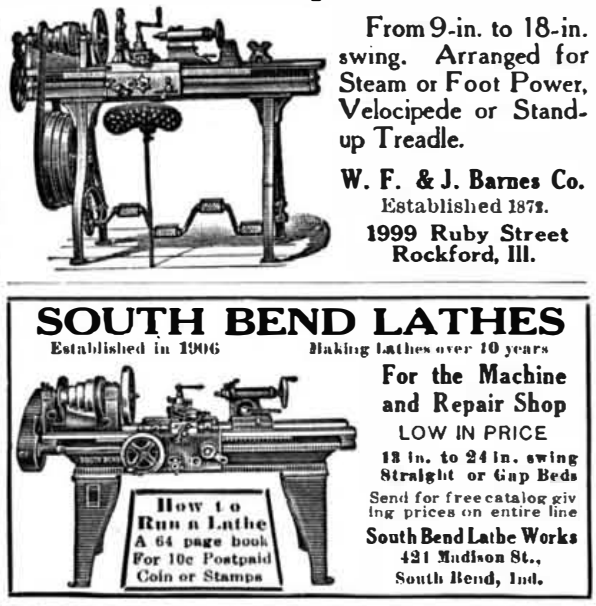

ASBESTOS

Quantity W We produce all grades at our world famous
BEL ASESTOS MINES In Canada. We also card For anything you want in Asbestos, turn to
KEASBEY \& MATTISON COMPANY AMBLER, PENNA, U. S. A.

WELL ${ }_{\text {PAIIING }}^{\text {RILELL }}$

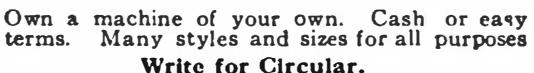
Write for Circular.
WILLIAMS BROS., 434 W. State St., Ithaca, N.Y.

Experimental and Model Work

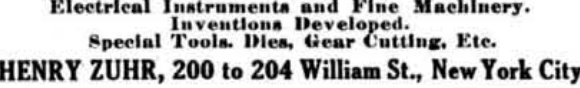
NOVEL TIES \& PATERTED AR TICLES

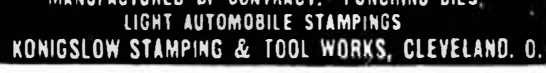

MASON'S NEW PAT. WHIP HOIST for Outrigger hoists. Faster than Elevatoros. and holst
direct from teams. saves. handing at less expense. Manufactured by VOLNEY W. MASON \& CO., Inc.
Providence, R. I. U. S. A.

THE BRIDGEPORT CHAIN CO. SpecialistsinSmallWire Shapes \& Flat Stampings Bridgeport, Conn.

THESCHWERDTLE STAMP CO.
SIEEL STAMPS LETIERS \& FIGURES.
BRIDGEPORT CONK.

Magical Apparatus

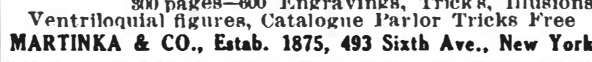

The Boys Magazine

Tell Your Boy About This! Boys, you can
make good money each month selling ness experience of great value later on in life.
. Write us today for 5 copies. Send no money.
THE SCOTT F. REDFIELD CO., Dept. A72, Sarthport, Pa.

\begin{tabular}{|c|}
\hline 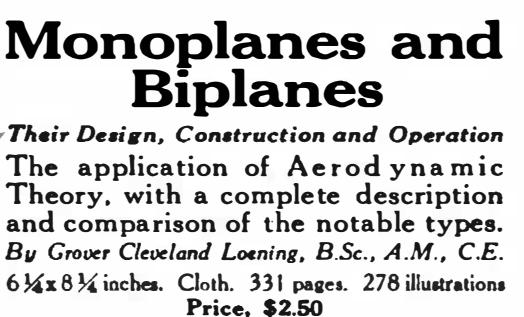 \\
\hline 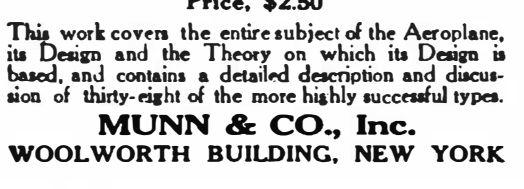 \\
\hline
\end{tabular}


streaks composed of short, brittle cells that was appointed to look into the matter with little strength. Such portions should Consider where the Government would frequently met with in yellow poplar and those highly disturbed conditions.

may be merely a stain which does not The report of March 15th of that diswhich does. Sapstain does not weaken inguished Committee may here be quoted unless it is in made by worms, borers, teredo, etc., reduce strength in proportion to their compained by decay.
Where various kinds of woods are being used on the same operation the question Sometimes it is a question of excluding a certain species entirely, again merely in nate mixing. Philippine mahogany, for type of propellers, and the inspectors and manufacturers frequently are at a loss to and feel of the wood are usually enough for a person familiar with them, need is which can always be relied upon in cases ducts which are distinct on a smooth end magnifier is used, collectively without it. marked with narrow white lines, some long, some very short, and mostly without any regularity of spacing. With the lens of white beads, each bead corresponding to the cross-section of a resin duct. "With Phillipine mahogany as quickly as he and apply the lens.
Philippine mahogany is not the name of tree but a trade term for a group of closely related woods. It corresponds exactly to our use of the term "southern pine" to designate the wood of any one which grow together in the South. And and are separated commercially on a so far in vain, to find some specific characters which are constant, but the individual variations seem to cover as wide a range
as those of different species. Hence it seems safe to follow the present practice as red lauan and the harder, stronger Another problem is the separation of the African and the tropical American both acceptable, it is not considered good practice to mix them in a propeller. Here this time so the casual observer may read. Narrow white lines which appear as
though marking rings of growth, sometimes close together, sometimes widely true mahogany from tropical America, the writer knows no exception to this statement. If these lines are examined with a lens they will not show the beaded
or dotted nature previously described for the Philippine substitute. Some of the harder grades of genuine mahogany have
some of the pores filled with lime deposits but they are irregularly scattered instead centric rings. More commonly the pores as plugged wie absent in the Philippin material they furnish additional aids in identification.
The so-called "practical" man is inclined to look upon these methods as needless of mistaken identity of woods used in
propellers which have come to the writer's notice emphasizes the need of some refined should serve, not as an excuse for careless selection, but as an incentive for more thorough analysis of its properties. Only them with discrimination.

The Government's Emergency Construction Contract

into the scheme of things and the Govern out its larger policies in regard to these matters without let or hindrance from the contractor; in other words it maintains its control of its own work

The proof of the pudding is in the eating and one naturally inquires how the contract has worked out. The answer is that and fifty contracts involving over $\$ 500$, 000,000 worth of work and the consensu of opinion among people who know is that
it has been more than a success. This is not an assertion that it produced 100 pe cent efficiency. Consider the changes
backing and filling, the tearing down an building up, and the violent eruptions that have beset the building program. This was advance made in the industries in the at to push the will its plan and scope but paying only which is so reasonable as to be above the "The Committee therefore advises for onment Division the work by the Cannown as 'cost of the work plus a sliding The building industry knew that an un recedented condition would have to be structure of this great country to its very ures to be undertaken within a year with
und every operation starting the minute it was meagre and hastily studied plans were vailable.

tion of the Construction Division-the administrative and supervisory organization carried out their part of the work. Their saved the trickling leakage from eroding away the mighty structure. On the con-
trary they were like those we may have avalanche, quickly organized, reached out and grasped the resources that were availWith the aid of the contracting industry the Division has in a very great measure otherwise would have been not only uncontrollable, but which might have swept away the very structure of our war preparation itself. The form of contract de-
vised by the War Industries Board, in the hands of able contractors, has been one of Construction Division in bringing the vast building program through on time.

\section{Machinery in the Household} (Concluded from page 216)

utilized, expert assistance employed, and and transfer of materials be taken adsurmise in what guises these changes may appear and to endeavor to picture their that the cld order is passing, and that we are at the threshhold of a revolution in advance made in the industries in the cy sticking his finger in the hole in the dike utilization
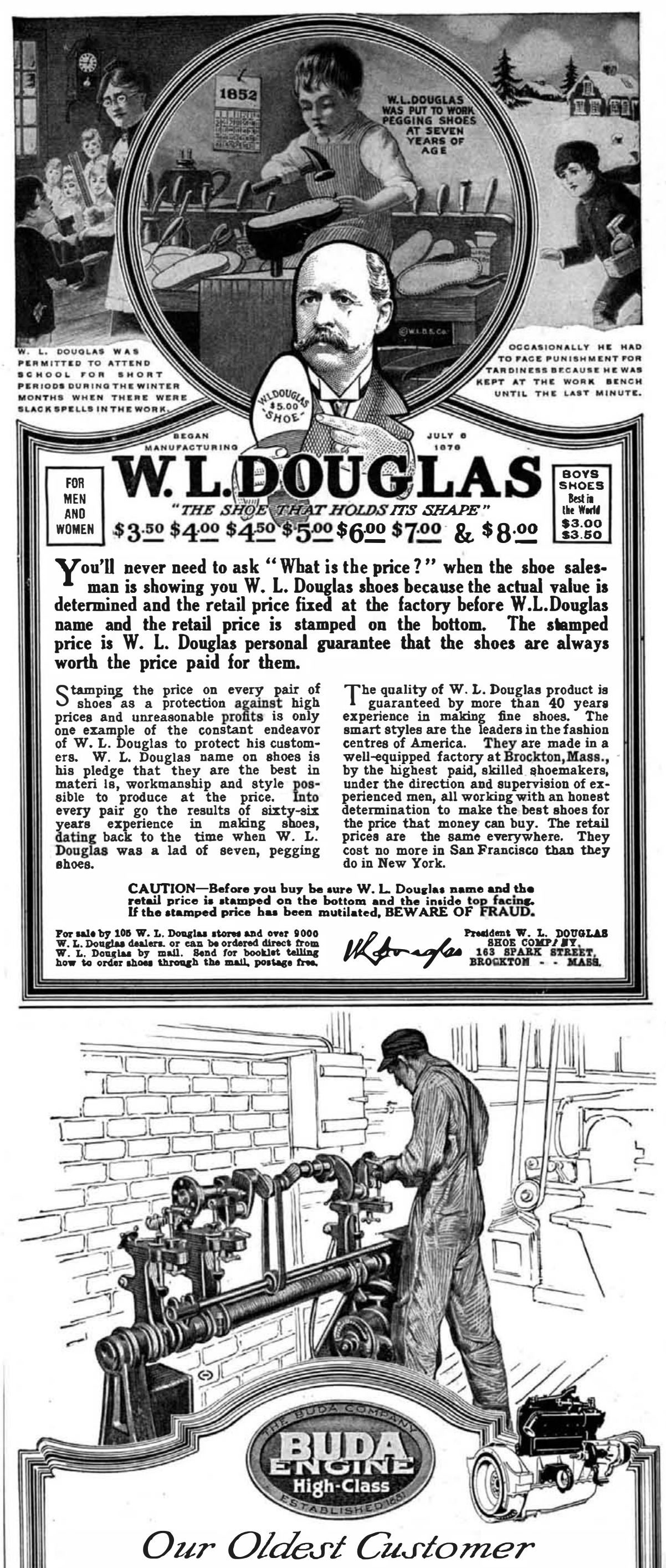

-is still with us! Buyer of the very first of BUDA ENGINES, maker of one of the greatest trucks ever built, he is still with us?

Better still, most of our customers are of the stillwith-us sort. Despite keen and varied competition the very leaders among truck and tractor builders continue year after year to buy in vastly increasing numbers "those BUDA ENGINES that never seem to wear out."

This means - what? It means that the BUDA ENGINE was right at first and is right now-not merely "good," but a fine,
sturdy product, thoroughly high-class clear through - and for keeps.

Made by The BUDA COMPANY, Harvey, (Chicago Suburb), Ill.

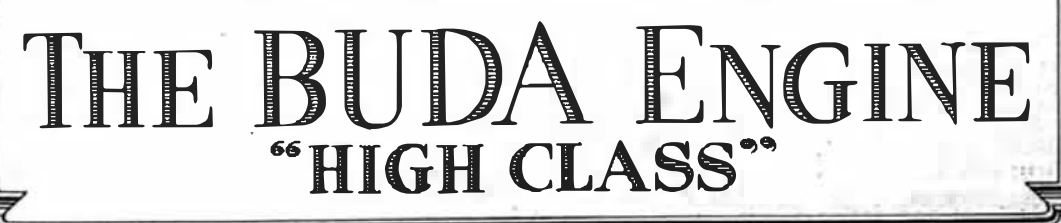

